\title{
Factors Associated With Intention To Quit Smoking Among African American Pregnant Women
}

\author{
Naomi Modeste, Jerry Lee, V. Joyce Lim, Dixon Anjejo \\ Loma Linda University, School of Public Health
}

\begin{abstract}
The purposes of this study were: 1) to determine beliefs salient to African American women quitting smoking while pregnant; 2) to determine how these beliefs relate to African American Women's intent to quit smoking while pregnant. The study had two-phases. First, qualitative data was collected in focus groups among 49 pregnant women, recruited from the Black Infant Health Program in San Bernardino County. Second, guided by the findings from the focus group, and based on the theory of planned behavior, a questionnaire was developed, pre-tested, and used as the instrument for collecting quantitative data. One hundred and fifty-six women ages 18-52 years completed the questionnaire. Of these, 97\% percent were current smokers and $21 \%$ had tried quitting in the past. Perceived control was the strongest predictor of intention, followed by attitude. Findings from this study will be used to plan a smoking cessation intervention for African American Pregnant women.
\end{abstract}

(C) 2004 Californian Journal of Health Promotion. All rights reserved.

Keywords: African American, pregnant women, intentions, quit smoking

\section{Introduction}

The priority population for this research was African American pregnant women in San Bernardino County with special efforts directed to pregnant women. There are 150,201 African Americans in the County of San Bernardino of which $91 \%$ live in the incorporated areas. Overall, the current smoking prevalence among the African Americans in San Bernardino County is $24.1 \%$, the highest rate when compared to other racial / ethnic groups. The tobacco industry targets ethnic minorities portraying tobacco use as "cool" and exciting and associated with a successful, flamboyant lifestyle. Sadly, these consumers do not believe that they are being misled by the tobacco industry, nor are they aware that the tobacco industry targets African Americans for business reasons (Yerger \& Malone, 2002).

Approximately 25\% of U.S. women who become pregnant are smokers at the time they learn they are pregnant. Although a majority continues to smoke throughout pregnancy, studies have shown that $23 \%-40 \%$ of these women spontaneously quit after learning they are pregnant (Mosher \& Pratt, 1987; Fingerhut, Kleinman \& Kendrick, 1990). Of these, 30\% remain smoke-free and $70 \%$ relapse within six months of delivery (RWJ, Smoke Free Families RFP 1999). Of 213 African American females in San Bernardino County Black Infant Health (BIH) program, 51 reported smoking during pregnancy (BIH Records, 1999). In San Bernardino county, high infant mortality and low birth weight babies among Black pregnant women is a serious problem, contributing to high mortality rates (County Data Book, 1999). While there are many factors contributing to this high rate of infant mortality and to low birth weights in the Black population, at least two, smoking throughout pregnancy and second hand smoke, are modifiable factors.

Lack of information is an obstacle while working with this priority population because there is not enough knowledge about how to attract and help African American females who continue to smoke throughout pregnancy. There is a scarcity of studies of African American 
pregnant smokers from which we can learn what predicts their success or failure in smoking cessation (Savitz, Dole, Terry, Zhou, \& Thorp, 2001).

Of a total of 150 articles on smoking cessation during pregnancy, eight studied minorities and only four of those addressed the African American Population (Lamb, Albretcht, \& Sereika, 1998; King, Borrelli, Black, Pinto, \& Marcus, 1997; Lillington, Royce, Novak, Ruvalcaba \& Chlebowski, 1995; O’Campo, Faden, Brown, \& Gielen, 1992). A more recent study also reported few studies addressing African American pregnant smokers (Savitz et. al., 2001). The literature, however, indicated factors that increase the risk of continuing to smoke that maybe applicable to the African American population. These are: high level of smoking prior to pregnancy (Isohanni, Oja, Moilanen, Koiranen, \& Rantakallio, 1995); long duration of the smoking habit (Woodby, Windsor, Snyder, Kohler \& Diclemente, 1999); lack of important knowledge about the dangers of smoking (Haugland, \& Haug, 1995); smoking by the woman's mother and partner (Olsen, 1993); high parity (Cnattingius \& Lamb, 1995; Olsen, 1993); being further along in the pregnancy (Hutchison, Stevens, \& Collins, 1996); being older (Severson, Andrews, Lichtenstein, Wall, \& Zoref, 1995); infants father not living in the home (Cnattinguis, Lindmark, \& Meirik, 1992); fewer years of education (Halal \& Victora,1993); negative stress situations (Wergeland, Strand, \& Bjerkedal, 1996); lower social status and income (O’Campo, et al., 1992; McBride, Pollak, Bepler, Lyna, Lipkus \& Samsa, 2001); lack of confidence in one's ability to quit (Crittenden, Manfredi, Lacey, Warnecke, \& Parsons, 1994); a positive attitude toward smoking (Haugland, \& Haug, 1995); being unmarried and an urban dweller (Isohanni et al., 1995).

\section{Methodology \\ Design and Theory}

The study design was a two-stage assessment using a qualitative procedure followed by quantitative data collection. The first stage used a set of open-ended questions with seven focus groups, aimed at determining: a) what they believe would be the outcomes of quitting smoking during pregnancy; b) who would support or not support them in the attempt; c) what situational factors might facilitate or hinder their attempt to quit, and d) any other factors they believe would influence their decision and ability to quit smoking. The results from these questions were used to develop a questionnaire for the second stage.

The theoretical perspective that was utilized in this research is the theory of planned behavior (Ajzen, 1991, 1992). The theory of planned behavior (see Figure 1) has been used by other researchers to predict intention to change behavior and in smoking cessation (Norman, Conner, \& Bell, 1999; Godin, Valois, Lepage, \& Desharnais, 1992). We selected the theory of planned behavior as the most appropriate for this research. In the theory of planned behavior, behavior is determined by intention to perform a particular behavior and the degree to which a person perceives he or she has control over the behavior. Intention is determined by the attitude toward the behavior, the subjective norm, and the perceived control over the behavior. Attitude is determined by the salient expected outcomes of the behavior and the evaluation of each salient outcome. Subjective norm is determined by what important others want them to do and the motivation to comply with what they want. Perceived control is determined by the beliefs regarding availability of resources and opportunities necessary to carry out the behavior. 


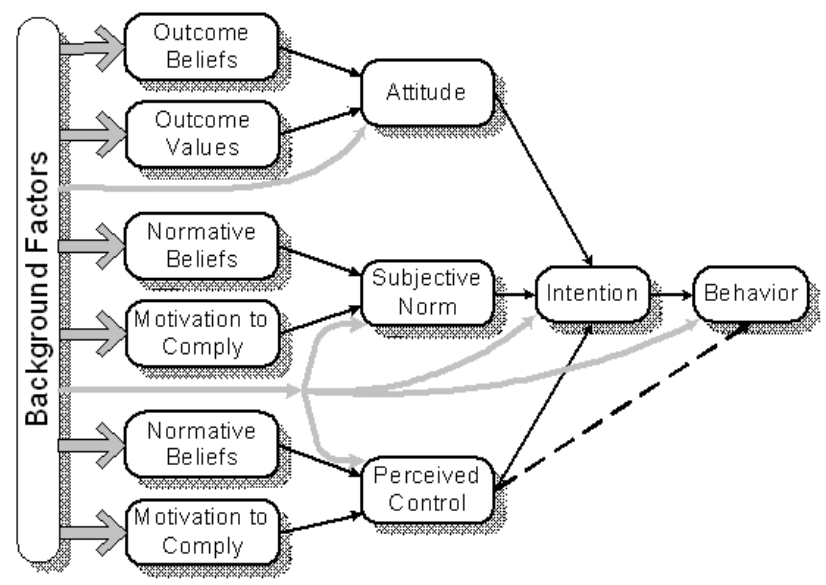

Figure 1

Theory of planned behavior. Based on Azjen (1991).

\section{Subject Selection}

Participants for the study were mothers 18 years and older selected from the African American communities in San Bernardino County. We used a convenience sampling technique. Only women who volunteered to participate and were pregnant at the time were included in the study. Women younger than 18 or not pregnant were excluded from the study.

\section{Instrumentation}

Using information gathered from the first stage, qualitative data collection, a questionnaire, incorporating the theory of planned behavior, was developed and pre-tested among similar women in the priority population $(n=10)$. After review and final changes, this questionnaire was used as the instrument for data collection. The questionnaire included nine sections with several questions to ascertain the respondents' smoking behavior and beliefs, outcomes that may happen if they quit smoking while pregnant, values of quitting smoking while pregnant, what others think about them smoking while pregnant, their expectations if they quit while pregnant, how difficult or easy it is for them to quit while pregnant, as well as demographic information.

\section{Data Collection}

Prior to collecting the data, sites serving African American pregnant women were contacted for a list of women who were known smokers. We involved outreach workers in the community to assist in bringing the women to the center for convening the focus groups as well as for completing the questionnaires. Seven focus groups were conducted. At each focus group session a letter of consent was presented to each woman to read and sign. A set of prepared questions were asked regarding expected outcomes of quitting smoking while pregnant, persons whom the women thought of when they thought about quitting while pregnant, and the resources or opportunities that would be necessary if the woman was to quit smoking while pregnant. The women were encouraged to participate and respond appropriately. The responses from the groups were taped and transcribed then sorted for specific information. Based on this information a questionnaire was constructed that assessed all components of the theory of planned behavior.

In order to reach women to complete the questionnaire for the second part of the data collection, recruitment flyers were distributed within agencies in the community that serviced African American pregnant women. The flyers contained a coupon to be exchanged for $\$ 10$ cash and a coupon redeemable at a local market after completing the questionnaire. Prior to completing the questionnaire, each woman was 
given a consent form to sign. Each participant met at a site convenient to them and completed the questionnaire, which was self-administered. For anonymity, participants were asked not to write their names on the questionnaire. The completed questionnaires were collected and placed in an envelope until time for data entry.

\section{Data Analysis}

Data from the qualitative section, focus group responses, were transcribed and analyzed. The quantitative data were checked, recorded, entered and analyzed using the Statistical Packages for the Social Sciences (SPSS). Descriptive statistics were calculated for all variables. In the theory of planned behavior 1) attitudes are determined by a function of the product of each belief about an outcome with the value of that outcome, 2) subjective norm by the product of the normative belief about what each important other wants with the motivation to comply with that person and 3) perceived control by the product of each belief about the availability of a necessary resource or opportunity with the power of that resource or opportunity to give the individual control. We created all these product scores. Using path analytical techniques, a series of four multiple regression analyses were performed one regressing intention on attitude, subjective norm, and perceived control, one regressing attitude on the outcome products, one regressing subjective norm on the normative products and one regressing perceived control on the control belief products. Bivariate correlations of all these associations were also calculated.

\section{Results}

For stage one, the qualitative study of the research, seven focus groups convened with 49 pregnant women participating. Content analysis resulted in 39 outcome beliefs, 30 control beliefs, and 24 normative beliefs. These beliefs will be listed in the discussion of our quantitative results.

Results of the quantitative study showed that 156 African American pregnant women completed the questionnaire. They ranged in age from 18 to 52 years old, with the majority (49\%) within the ages of 18 and 24 years; 41\% said they completed the 12 th grade and $37 \%$ had a high school diploma. They were asked to indicate their family income and most (64\%) had an annual family income less than $\$ 10,000$. Forty-three percent were expecting their baby more than six months from the time of data collection, while 32\% expected their baby within four to six months and $25 \%$ in three months or less.

Ninety-seven percent reported that they were current smokers. Of these, $46 \%$ were average smokers, 29\% heavy smokers, and 24\% light smokers. Most of the women (64\%) reported smoking for seven days within the previous week of data collection and $49 \%$ smoked seven or more cigarettes during that week. However, the majority $(73 \%)$ said that they generally smoke 10 or less cigarettes per day. The majority (71\%) indicated that they had quit smoking at least once within the last year, but $29 \%$ never tried to quit during that time. Participants were asked if they were seriously thinking about quitting smoking, and the majority (53\%) were seriously thinking about quitting within 30 days; $37 \%$ within six months and $10 \%$ were not thinking about quitting at all. The most frequent smoking time for $61 \%$ was the first hour after waking. Fifty-nine percent would not smoke if they were too ill to get out of bed, but $41 \%$ said that they would smoke even if they were too ill to get out of bed, and $72 \%$ felt that the first cigarette in the morning would be the one most difficult to give up.

Figure 2 shows a summary of a series of analyses attempting to determine factors most highly associated with intentions of pregnant African American women to stop smoking while pregnant. In Figure 2 we also note that the general prediction of intention is not as good as we would like in this study. This may be because of a tendency for women not to pay close attention to each item on the questionnaire. 


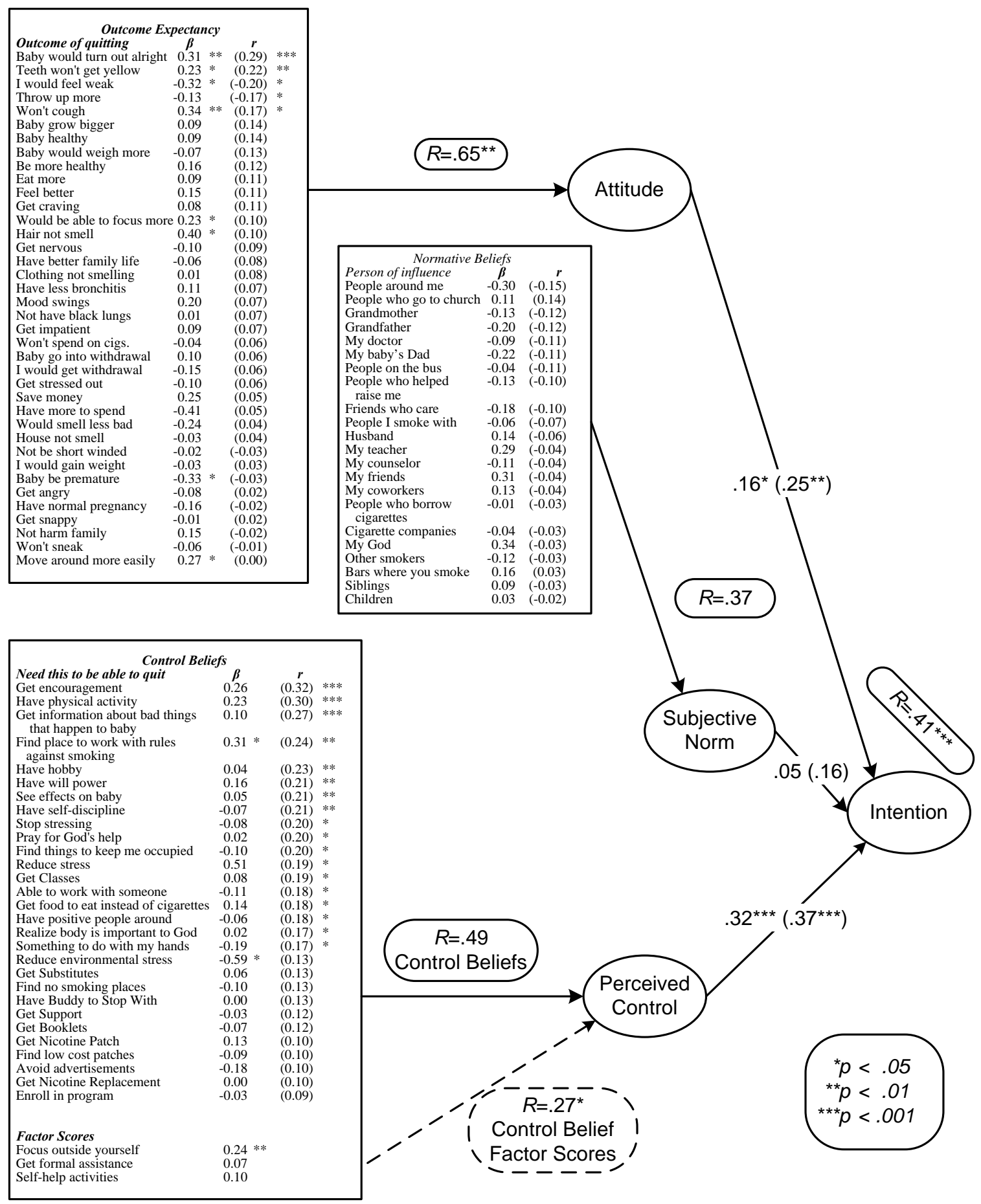

Figure 2

Path model showing how the theory of planned behavior components relate to the intention to quit smoking while pregnant. Numbers in parentheses are Pearson correlations. Numbers not in parentheses are standardized regression coefficients. Rs are the multiple correlations from multiple regression analysis. 
Perceived control was the strongest predictor of intention to quit smoking while pregnant $(\mathrm{p}=$ $<.001)$. Attitude was the next strongest predictor of intention ( $\mathrm{p}=<.01)$. Subjective norm seemed to play a little role in the prediction of intention $(p=<.05)$. Attitude was best predicted by beliefs that outcomes of quitting would involve the baby turning out alright, that teeth would not yellow, and that the mother would not feel weak if she quit (negative correlation) or cough. A concern that the mother would throw up more if she quit was associated with a more negative attitude toward quitting but this association was no longer significant when other outcome expectancies were controlled. Four beliefs that were not significant predictors of attitude by themselves were significant when other beliefs were controlled. In fact one of these (a belief that if the woman quit smoking her hair would smell better) was the single strongest predictor of a positive attitude toward quitting when all other variables were controlled. A belief that the baby might be premature if the mother quit was also associated with the mother having a negative attitude toward quitting smoking.

No normative belief predicted the subjective norm. As can be seen in figure 2, regarding perceived control, quite a number of control beliefs were associated with a belief that the mother was in control of whether she could quit. The three strongest, being a belief that she would need encouragement, physical activity, and information about the bad things that would happen to the baby if she continued smoking. However, only one of the variables that had a bivariate association with perceived control was significant in predicting perceived control when all other variables were controlled - namely, finding a workplace that did not allow smoking

The data suggest that pregnant African American women trying to quit smoking must have positive people around them, to be able to work with someone and get support and encouragement. Focusing outside of themselves, having a hobby and having something to do with their hands were predictors of perceived control. A significant perceived control variable was to "stop stressing." Another significant control belief was involvement in physical activity. Praying to God and the realization that their body is important to God were predictors of the sense of control over quitting.

Important outcome beliefs involved seeing the effects of smoking on the baby and getting information about bad things that could happen to the baby. Keeping occupied and finding a place to be or work where there are rules against smoking were also important predictors of control. Certain physical effects on the mother were predictors of attitude toward quitting.

\section{Discussion}

Although the theory of planned behavior has been widely used, its use in the area of smoking cessation is somewhat limited (Conner \& Sparks, 1996). However, our findings on perceived control as a primary predictor of intention to quit corroborate findings from Norman, Conner, \& Bell, (1999), Godin et. al., (1992), and Godin \& Kok (1996) who applied the theory to smoking cessation.

Results from the analysis suggest that the intention to try to quit smoking while pregnant was most strongly influenced by the degree to which the mother believes that she can control the behavior of smoking and next most strongly by their attitude toward quitting. Perceived control, the most potent predictor of intention, was most strongly predicted by a group of resources and opportunities that might best be characterized as focusing outside the self. The next strongest predictor of intention, attitude toward quitting, was most strongly predicted by four variables: a belief that the "baby would turn out right" if the mother quits, that the "teeth will not get yellow", that the mother will "not feel weak" and "throw up".

The general prediction of intention was not as positive as we would have liked and this may have been because some mothers did not take the time to focus closely on the questions in each section. As noted earlier, subjective norm played little or no role in predicting intention to quit smoking while pregnant in this group of African American women. This may be because the mothers believed that practically all of the important others in their lives did not want them to smoke while pregnant. It was also noted that 
the opinion of no specific person predicted the subjective norm and this might be because there was little variation in these opinions. Practically all participants indicated that they wanted to quit while pregnant.

This study is not without its limitations and therefore, the preceding results should not be treated as representative of all African American pregnant smokers. The questionnaire was based on the results of the women who participated in the focus groups. We utilized a convenience sampling technique and offered a monetary incentive for completing the questionnaire and people may have consented because of the incentive. This study, nevertheless, provided important information increasing our knowledge regarding African American pregnant smokers and their beliefs about the outcome of quitting while pregnant. Findings from this study will also improve on the paucity of literature on maternal smoking among African Americans. Moreover, the findings will allow us to plan culturally appropriate smoking cessation interventions as described by these women.

\section{References}

Ajzen, I. (1991). The theory of planned behavior. Organizational Behavior and Human Decision Processes, 50, 179-211.

Ajzen, I. (1992). The directive influence of attitudes on behavior. In P. M. Golwitzer \& J. A. Bargh (Eds.), The psychology of action: Linking cognition and motivation to behavior (pp. 385-403). New York: The Guilford Press.

Cnattingius, S., Lindmark, G., \& Meirik, O. (1992). Who continues to smoke while pregnant? Journal of Epidemiology and Community Health, 46, 218-21.

Cnattingius, S., \& Lambe, M. (1995). The importance of preventing smoking by women: Especially smoking during pregnancy. Lakartidningen, 92, 4677-8.

Conner, M., \& Sparks, P. (1996). The theory of planned behavior and health behaviors. In M. Conner \& P. Norman (Eds.), Predicting health behavior (pp. 121-162). Buckingham, England: Open University Press.

Crittenden, K. S, Manfredi, C., Lacey, L., Warnecke, R., \& Parsons, J. (1994). Measuring readiness and motivation to quit smoking among women in public health clinics. Addictive Behaviors, 19, 497507.

Fingerhut, L. A., Kleinman, J. C., \& Kendrick, J. S. (1990). Smoking before, during, and after pregnancy. American Journal of Public Health, 80, 541-544.

Godin, G., Valois, P., Lepage, L., \& Desharnais, R. (1992). Predictors of smoking behavior: An application of Ajzen's theory of planned behavior. British Journal of Addiction, 87, 1335-1343.

Godin, G., \& Kok, G. (1996). The theory of planned behavior: A review of its application to health related behaviors. American Journal of Health Promotion, 11(2), 87-98.

Halal, I. S., Victora, C. G. (1993). Determining factors of smoking habit and its cessation during pregnancy in an urban locality in the Southern region of Brazil. Revista de Saude Publica, 27(2), 105-12.

Haugland, S., \& Haug, K. (1995). What determines smoking habits in pregnancy? A qualitative study among pregnant smokers. Tidsskr Nor Laegeforen, 115, 2106-2109.

Hutchison, K. E., Stevens, V. M., \& Collins, F. L. (1996). Cigarette smoking and the intention to quit among pregnant smokers. Journal of Behavioral Medicine, 19, 307-136

Isohanni, M., Oja, J., Moilanen, I., Koiranen, M., \& Rantakallio, P. (1995). Smoking or quitting during pregnancy: associations with background and future social factors. Scandinavian Journal of Social Medicine, 23(1), 32-8.

King, T. K., Borrelli, B., Black, C., Pinto, B. M., \& Marcus, B. H. (1997). Minority women and tobacco: implications for smoking cessation interventions. Annals of Behavioral Medicine, 19, 301-13. 
Lamb, J. M., Albretcht, S. A., \& Sereika, S. (1998). Consideration of factors prior to implementing a smoking cessation program. Journal of School Nursing, 14(1), 14-19.

Lillington, L., Royce, J. Novak, D., Ruvalcaba, M., \& Chlebowski, R. (1995). Evaluation of a smoking cessation program for pregnant minority women. Cancer Practice, 3(3), 157-63.

McBride, C. M., Pollak, K. I., Bepler, G., Lyna, P., Lipkus, I. M., Samsa, G. P. (2001). Reasons for quitting smoking among low-income African American smokers. Health Psychology, 20, 334340.

Mosher, E. D., \& Pratt, W. F. (1987). Fecundity, infertility and productive health in the United States, 1982. Vital statistics. Data from the national survey of family growth. Series 23, 14, 1-51.

Norman, P., Conner, M., \& Bell, R. (1999). The theory of planned behavior and smoking cessation. Health Psychology, 18(1), 89-94.

O’Campo, P., Faden, R. R., Brown, H., \& Gielen, A. C. (1992). The impact of pregnancy on women's prenatal and postpartum smoking behavior. American Journal of Preventive Medicine, 8(1), 8-18.

Olsen, J. (1993). Predictors of smoking cessation in pregnancy. Scandinavian Journal of Social Medicine, 21(3), 197-202.

Savitz, D. A., Dole, N., Terry, J. W., Zhou, H., \& Thorp, J. M. (2001). Smoking and pregnancy outcome among African American and white women in central North Carolina. Epidemiology, 12, 636642.

Severson, H. H., Andrews, J. A., Lichtenstein, E., Wall, M., \& Zoref, L. (1995). Predictors of smoking during and after pregnancy: A survey of mothers of newborns. Preventive Medicine, 24(1), 23-8.

Wergeland, E., Strand, K., \& Bjerkedal, T. (1996). Smoking in pregnancy: A way to cope with excessive workload? Scandinavian Journal of Primary Health Care, 14(1), 21-28.

Woodby, L. L., Windsor, R. A., Snyder, S. W., Kohler, C. L., \& Diclemente, C. C. (1999). Predictors of smoking cessation during pregnancy. Addiction, 94, 283-92.

Yerger, V. B., \& Malone, R. E. (2002). African American leadership groups: Smoking with the enemy. Tobacco Control, 11, 336-345.

\title{
Acknowledgment
}

The authors wish to acknowledge the Westside Brighter Vision Foundation in San Bernardino, for the role it played in providing the infrastructure for this community-based research. We are very grateful to the Legacy Foundation, Washington DC for funding this project. Without this grant from Legacy, the research project would not have been possible.

\author{
Author Information \\ Naomi Modeste, DrPH \\ Loma Linda University \\ School of Public Health \\ Loma Linda, CA 92350 \\ Ph: 909-558-4575 \\ E-Mail: nmodeste@sph.llu.edu \\ Jerry Lee, PhD, Professor \\ Loma Linda University \\ School of Public Health \\ Loma Linda, CA 92350
}


V. Joyce Lim, DrPH, Retired Professor

P O Box 484

Loma Linda, CA 92354

Dixon Anjejo, MA, DrPH Student

Loma Linda University

School of Public Health

Loma Linda, CA 92350

* corresponding author 